\title{
Polymorphism and evolution in the butterfly Danaus chrysippus (L.) (Lepidoptera: Danainae)
}

\author{
DAVID A. S. SMITH, DENIS F. OWEN*†, IAN J. GORDON $\ddagger$ \& AGOROACHAI M. OWINY§ \\ Department of Biology, Eton College, Windsor SL4 6EW, †School of Biological and Molecular Sciences, Oxford Brookes \\ University, Headington, Oxford OX3 OBP, U.K., $\ddagger$ Department of Zoology, University of Nairobi, PO Box 30197, Nairobi, \\ Kenya and \$Department of Zoology, Makerere University, PO Box 7062, Kampala, Uganda
}

\begin{abstract}
Analysis of the genetic structure of a sample of the polymorphic butterfly Danaus chrysippus from Kampala, Uganda shows that the population is undergoing substantial evolutionary change. Comparison with samples from the same area going back to before 1900 , indicate that the frequency of form alcippus has increased from 16 per cent to 71 per cent (1909-91) while f. dorippus has decreased from 14 per cent to 2 per cent, f. aegyptius from 66 per cent to 24 per cent and $\mathrm{f}$. albinus from 4 per cent to 3 per cent. Genotype frequency differences between the sexes at two of the three loci examined suggest that a balanced polymorphism is maintained by opposing selective forces acting on males and females. Non-gametic (genotypic) disequilibrium between two pairs of unlinked loci indicates that natural selection is involved, again with sex differences. It is suggested that the polymorphism originated after hybridization of allopatric races which evolved during the Pleistocene but are now maintained sympatrically. The selective agents have not been identified but mimetic relationships, both Batesian and Müllerian, are almost certainly involved.
\end{abstract}

Keywords: allopatric evolution, D. chrysippus, mimicry, non-gametic disequilibrium, polymorphism, sympatric evolution.

\section{Introduction}

In much of Africa the butterfly Danaus chrysippus (L.) (Nymphalidae: Danainae) is polymorphic for colour and pattern. As it is both a Batesian model for several unrelated species, belonging to four different butterfly families (or subfamilies depending on the authority) and also a Müllerian mimic sharing in rings with several other unrelated unpalatable species, it is a remarkable exception to the rule that both Batesian models and Müllerian mimics are monomorphic (Owen, 1971; Smith, 1980; Gordon, 1984). The polymorphism is best developed in East and Central Africa, especially in Uganda; there are also large areas, both within and outside Africa, where the butterfly is monomorphic and this is the general rule, with only local exceptions, throughout its extensive Palaearctic, Oriental and Australasian range.

In East Africa there are four main colour forms, still referred to by their traditional Latin names: aegyptius (incorrectly called chrysippus by many previous investi-

\footnotetext{
*Correspondence.
}

gators in the East African region), alcippus, dorippus and albinus (Fig. 1). Colour plates can be found in Rothschild et al. (1975) and Smith (1980).

Many alcippus have only a small white patch in the hindwing or simply white scaling lining the veins; these we refer to as weak alcippus (also known as alcippoides); similarly there are weak albinus (also known as semialbinus). Many dorippus have a variable number of 'aegyptius' subapical spots on the underside of the forewing; these are also called transiens. In all four forms the orange ground colour may be completely or partially replaced by brown.

Forms aegyptius, alcippus, dorippus and albinus are involved in a Müllerian mimicry complex with Acraea encedana Pierre and $A$. encedon (L.) (Acraeinae) and are also models for many presumed Batesian mimics, particularly Hypolimnas misippus (L.) (Nymphalidae). Maps showing the distribution of the forms of $D$. chrysippus in Africa are given in Owen \& Chanter (1968), Owen (1971), Rothschild et al. (1975) and Pierre $(1973,1980)$. The switch between orange and brown ground colour phenotypes (which have not received Latin names) probably has little impact on 

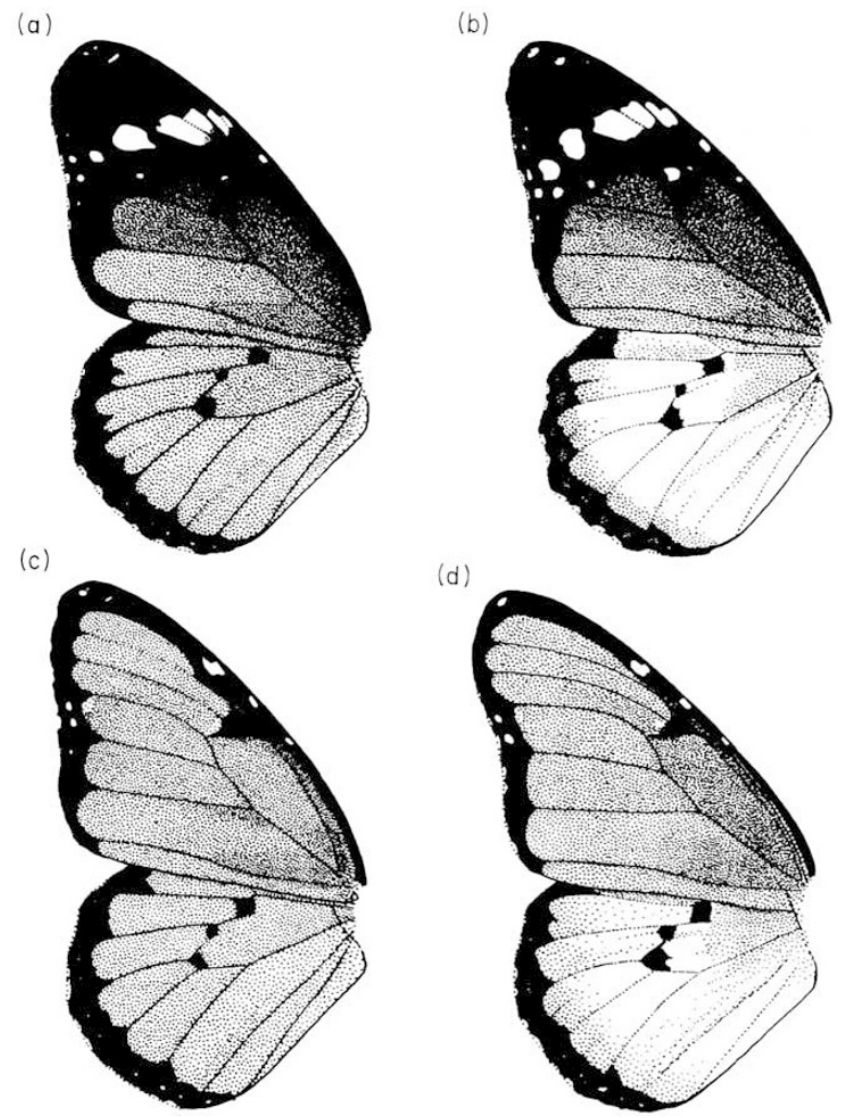

Fig. 1 Colour forms (f.) of Danaus chrysippus. (a) f. aegyptius. (b) f. alcippus. (c) f. dorippus. (d) f. albinus. The black and white areas are as shown; the stippled areas are either orange or brown.

generalized mimetic resemblance (Gordon, 1984), especially as many of the mimics are similarly variable; Smith (1980) has suggested that the orange-brown polymorphism relates to climatic adaptation, possibly through thermoregulation, influencing activity levels and, in particular, courtship behaviour.

The genetics of the polymorphism in $D$. chrysippus involves three loci, $A, B$ and $C$ (Smith, 1975a). The A locus controls the pattern of the hindwing, the $A$ allele giving brown or orange aegyptius and $a a$ a large white patch (alcippus). Aa heterozygotes vary between having a reduced white patch, white scaling lining the veins (both scored as weak alcippus) or no trace of white (scored as aegyptius); hence not all heterozygotes are phenotypically distinguishable from $A A$ homozygotes. Estimates for the penetrance of $a$ in heterozygotes, based on breeding at Dar es Salaam, Tanzania are 74.4 per cent $(N=47)$ (Smith, 1975a) and 65.6 per cent $(N=66)$ (Smith, 1980) with an average of 70 per cent. An estimate of 69.7 per cent penetrance for the Kampala sample $(N=211)$ suggests good agreement with Dar es Salaam but assumes the alleles are in
Hardy-Weinberg equilibrium, which they are unlikely to be (see below). At Kampala, penetrance of $a$ is nearly equal in the two sexes whereas at Dar es Salaam it is 24 per cent higher in males than in females. The $\mathrm{B}$ locus controls ground colour, $B$ giving brown and $b b$ orange. Many heterozygotes are detectable but they are variable: $B b$ genotypes always have a brown forewing and a little brown on the costal margin of the hindwing but the hindwing may be entirely brown as in $B B$ homozygotes. The B locus was first identified by Clarke et al. (1973) and confirmed by Smith (1975a). The $\mathrm{C}$ locus controls the forewing pattern, $C$ giving dorippus (or albinus when combined with a white hindwing), and $c c$ giving aegyptius (or alcippus when combined with a white hindwing). Many $C c$ heterozygotes can be recognized phenotypically by the presence of pale subapical spots on the underside of the forewing (transiens). At Dar es Salaam, Tanzania, the expressivity of $c$ in $C c$ genotypes is influenced by the B locus, 45 per cent $(N=129)$ of $b b C c$ heterozygotes being transiens compared with 74.6 per cent $(N=173)$ of $B-C c$ (Smith, 1980).

The $\mathrm{B}$ and $\mathrm{C}$ loci are closely linked with a recombination value of 1.9 per cent ( 3.8 per cent in males only as meiosis is probably achiasmatic in females). The A locus assorts independently of B and C at Dar es Salaam (Smith, 1975a, 1980) and also did so in crosses between alcippus ( $a a \mathrm{~B}-$ ) from Sierra Leone and subspecies petilia $(A A b b)$ from Australia (Clarke et al., 1973).

Here we report on genotype frequency in a sample of $D$. chrysippus obtained at Kampala, Uganda, in December 1991 and present evidence indicating that powerful natural selection is operating at the present time and that a considerable evolutionary change has occurred in the past 91 years (approximately 1092 breeding generations).

\section{Materials and methods}

\section{Source of material}

D. chrysippus is an abundant butterfly and large samples are easily obtained by using an ordinary butterfly net. In December 1991 we collected a sample in the Kampala area at sites where previous samples had been obtained by us (1964-66, Owen \& Chanter (1968); 1972, A.M.O., unpublished data). We also examined two samples in the Hope Entomological Collections, Oxford, which had been randomly obtained on the instructions of Professor E. B. Poulton. One of these, obtained by C. A. Wiggins in 1909-12, is from the same area as the more recent samples, whereas the other comes from Kome Island (just off 
Table 1 Frequency (percentage) of phenotypes and genotypes in a sample of Danaus chrysippus collected in the Kampala region, Uganda, in December 1991

\begin{tabular}{llrrr}
\hline Form and colour & Genotype & Male & Female & Population \\
\hline alcippus, orange & aa $b b c c$ & 46.7 & 24.0 & 35.5 \\
alcippus, brown & $a a B-c c$ & 3.7 & 7.7 & 5.7 \\
weak alcippus (= alcippoides), orange & $A a b b c c$ & 26.2 & 24.0 & 25.1 \\
weak alcippus (= alcippoides), brown & $A a B-c c$ & 0.9 & 8.7 & 4.7 \\
aegyptius $\dagger$, orange & $A-b b c c$ & 15.9 & 24.0 & 19.9 \\
aegyptius $\dagger$, brown & $A-B-c c$ & 1.9 & 5.8 & 3.8 \\
albinus, orange & $a a b b C-$ & 0.9 & 0.0 & 0.5 \\
albinus-transiens, orange & $a a b b C c$ & 3.7 & 0.0 & 1.9 \\
weak albinus (= semialbinus), orange & $A a b b C-$ & 0.0 & 1.0 & 0.5 \\
dorippus, orange & $A-b b C-$ & 0.0 & 1.9 & 0.9 \\
dorippus-transiens, orange & $A-b b C c$ & 0.0 & 2.9 & 1.4 \\
Sample size & $A-b b C c$ & 107 & 104 & 211 \\
\hline
\end{tabular}

† Scored as chrysippus by some earlier workers, this name should be restricted to the similar but distinct Oriental and Palaearctic subspecies.

Entebbe in Lake Victoria), was obtained in 1946, and is included because $D$. chrysippus ranges widely and the colour forms (at a given time) are stabilized over relatively large geographical areas (Owen, 1971). Three earlier large collections, all mainly pre-1900, were examined: two in the Natural History Museum, London and one in the Hope Entomological Collections, Oxford. Although museum samples are notoriously non-random with rare phenotypes generally over-represented, in this case the phenotype frequencies in the three collections are in fact, surprisingly, formally homogeneous and this increases our confidence that they provide a realistic early baseline from which subsequent evolutionary changes are assessed.

\section{Results}

\section{Genetic structure of the Kampala population in 1991}

Table 1 lists the frequencies of phenotypes and genotypes in the Kampala sample obtained in 1991; Table 2 gives the frequencies of dominant and recessive phenotypes observed at each of the three polymorphic loci: $\mathrm{A}, \mathrm{B}$ and $\mathrm{C}$. At all three loci only a proportion of heterozygotes is distinguishable from dominant homozygotes and their scores are therefore combined. As the Uganda population of D. chrysippus is unlikely to be in Hardy-Weinberg equilibrium, it follows that the estimation of allele frequencies using the observed frequency of recessive phenotypes, which is the only method available to us, must be illegitimate.

There are several factors, known to apply either to the sampled population or to others in East Africa, which are expected to be inimical to the maintenance
Table 2 Frequencies of dominant and recessive phenotypes in a sample of 211 D. chrysippus from Kampala, Uganda

\begin{tabular}{|c|c|c|c|c|c|}
\hline \multirow[b]{2}{*}{ Locus } & \multicolumn{2}{|l|}{ Male } & \multicolumn{2}{|c|}{ Female } & \multirow[b]{2}{*}{$\chi_{(1)}^{2}$} \\
\hline & $\begin{array}{l}\mathrm{D} \\
(\%)\end{array}$ & $\begin{array}{l}\mathrm{R} \\
(\%)\end{array}$ & $\begin{array}{l}\mathrm{D} \\
(\%)\end{array}$ & $\begin{array}{l}\mathrm{R} \\
(\%)\end{array}$ & \\
\hline$A$ & 44.9 & 55.1 & 68.3 & 31.7 & $10.820^{* *}$ \\
\hline$B$ & 6.5 & 93.5 & 22.1 & 77.9 & $9.249^{* *}$ \\
\hline$C$ & 4.7 & 95.3 & 5.8 & 94.2 & 0.002 \\
\hline
\end{tabular}

$\mathrm{D}$, dominant; R, recessive. ${ }^{* *} 0.01>P>0.001$ (with Yates' correction).

of a Hardy-Weinberg equilibrium. (i) Selective elimination of $A a$ heterozygotes was observed at Kampala in 1964-66 from a comparison of the proportions of weak alcippus among adults reared from wild larvae in the laboratory and in the wild population (Owen \& Chanter, 1968). (ii) Sexual selection based on male heterozygote advantage is recorded in Tanzania (Smith, 1975c, 1981). (iii) Assortative mating for both B and C loci is known from Tanzania (Smith, 1984). (iv) Linkage disequilibrium for $\mathrm{B}$ and $\mathrm{C}$ loci is also present in Tanzania (Smith, 1980). (v) Both primary and secondary sex ratios generally deviate from 1:1 throughout East Africa (Smith, 1975b; I. J. Gordon, unpublished data) and both were low (female biased) in Uganda during 1964-66 (Owen \& Chanter, 1968). (vi) Migration has frequently been reported. Thus there are at least six possible factors which either singly or in combination are incompatible with the maintenance of a Hardy-Weinberg equilibrium. 
The data (Table 2) show highly significant sex differences for phenotype frequency at the $\mathrm{A}$ and $\mathrm{B}$ loci: in particular, $a a$ (white hindwing) is more frequent in males, and conversely, $A-$ (non-white hindwing) in females $(P<0.01)$; at the B locus, $B-$ (brown) females and $b b$ (orange) males exceed expectation $(P<0.01)$. These effects cannot result from orthodox sex linkage as the A, B and C loci all proved to be autosomal in breeding experiments on populations from Tanzania (Smith, 1975a), Kenya (I. J. Gordon, unpublished data), India (Smith et al., 1988), Sierra Leone and Australia (Clarke et al., 1973). Polymorphisms for sex-autosome translocations, however, cannot be ruled out, at least for the B locus (Smith, 1976b; I. J. Gordon, unpublished data).

In Table 3 we compare the observed $\mathrm{A}-\mathrm{B}$ and $\mathrm{A}-\mathrm{C}$ phenotype frequencies using Brandt and Snedecor's formula for Chi-squared. A null hypothesis, that the various combinations are expected to have equal frequencies in each sex, is rejected for both A-B $(P<0.001)$ and $\mathrm{A}-\mathrm{C}(P<0.05)$ phenotypes. Therefore we conclude that either selective forces causing differential survival or abnormal segregation mechanisms, presumably also maintained by natural selection, are operating to maintain very different phenotype frequencies in the two sexes; moreover, the mechanisms involved affect all three loci investigated, either individually (Table 2) or in combination (Table 3 ).

The nature of our data precludes further analysis: in particular it is impossible by direct count to quantify

Table 3 Observed numbers of A-B and A-C locus phenotypes in each sex of $D$. chrysippus compared with those expected if genotypes are homogeneous between sexes

\begin{tabular}{|c|c|c|c|c|c|}
\hline Genotype & $\begin{array}{l}\text { Male } \\
N\end{array}$ & $(\%)$ & $\begin{array}{l}\text { Female } \\
N\end{array}$ & $(\%)$ & $\begin{array}{l}\text { Totals } \\
N\end{array}$ \\
\hline$A-B-$ & 3 & 9.1 & 15 & 8.8 & 18 \\
\hline$A-b b$ & 45 & 51.2 & 56 & 49.8 & 101 \\
\hline$a a B-$ & 4 & 6.1 & 8 & 5.9 & 12 \\
\hline$a a b b$ & 55 & 40.6 & 25 & 39.4 & 80 \\
\hline Totals & 107 & & 104 & & 211 \\
\hline \multicolumn{6}{|c|}{$\chi_{(3)}^{2}=21.743 ; P<0.001$} \\
\hline$A-C-$ & 0 & 3.0 & 6 & 3.1 & 6 \\
\hline$a a C-$ & 5 & 2.5 & 0 & 2.4 & 5 \\
\hline$A-c c$ & 48 & 57.3 & 65 & 55.7 & 113 \\
\hline$a a c c$ & 54 & 44.1 & 33 & 42.9 & 87 \\
\hline Totals & 107 & & 104 & & 211 \\
\hline \multicolumn{6}{|c|}{$\chi_{(2)}^{2}=7.678 ; 0.05>P>0.02$} \\
\hline
\end{tabular}

$\chi^{2}$ values are calculated using Brandt and Snedecor's formula. $A-C$ - and a $C$ - genotypes are amalgamated to avoid low expected values. heterozygotes or linkage phases in double heterozygotes, thus ruling out exact tests for linkage disequilibrium. However, chi-squared tests applied to the six data subsets in Table 3 (A-B and A-C for each of males, females and the population), on the null hypothesis that association of genotypes in A-B and A-C combinations is random, are all non-significant. This result suggests there is no linkage disequilibrium between the $\mathrm{A}$ and $\mathrm{BC}$ chromosomes, either within sexes or in the population as a whole.

On the other hand, some form of disequilibrium is clear from the comparison of phenotype frequency distributions between sexes for both $\mathrm{A}-\mathrm{B}$ and $\mathrm{A}-\mathrm{C}$ combinations (Table 3 ). Among A-B phenotypes, the $A B, A b$ and $a B$ 'gametes' are all under-represented in males but exceed expectation in females; the opposite applies to the $a b$ 'gamete'. The data are not sufficient to determine if the effects at the $A$ and $B$ loci might be additive or interactive but suggest the former. A similar pattern, although involving mainly the $A$ locus, is found in the $A-C$ genotypes; $A C$ and $A C$ 'gametes' are more frequent than expected in females whereas $a C$ and $a c$ are over-represented in males. The A-B pattern suggests some kind of second-order, genotypic (nongametic or trigenic) disequilibrium within each sex. The sex differences could be caused by abnormal segregation of the type previously recorded at Dar es Salaam (Smith, 1976b) and Nairobi (I. J. Gordon, unpublished data) in which there is some form of association at segregation between autosomes and sex chromosomes, possibly resulting from Y-autosome translocations. As the $\mathrm{B}$ and $\mathrm{C}$ loci are closely linked (Smith, 1975a), some similarity between the $A-B$ and $A-C$ locus interactions is not unexpected.

\section{Changes in phenotype frequency}

Table 4 shows changes in the frequency of alcippus, aegyptius, albinus and dorippus in the Kampala area over 91 years, or slightly more, which is approximately 1092 breeding generations, the generation time (egg to egg) of $D$. chrysippus in Uganda being about 1 month. The heterozygote weak alcippus (=alcippoides) $(\mathrm{Aa} C \mathrm{Cc}$ ) is included under alcippus ( $a a c c$ ) and the heterozygote weak albinus ( $=$ semialbinus) $(A a C-)$ is included under albinus ( $a a C-$ ); this unfortunate loss of genetic information is unavoidable for reasons given below. Although the three mainly pre-1900 samples are unlikely to be strictly random, and we do not have the exact dates for many of the specimens, they provide a useful baseline against which to measure subsequent changes in phenotype frequency. Moreover, despite the caveats, we are surprised to find that they are formally 
Table 4 Comparison of phenotype frequencies of Danaus chrysippus around Kampala, Uganda, over 100 years (approximately 1092 generations)

\begin{tabular}{|c|c|c|c|c|c|c|}
\hline Source & Date & alcippus & aegyptius & albinus & dorippus & $N$ \\
\hline Natural History Museum (NHM), London & Mainly pre- 1900 & 38.2 & 27.6 & 9.2 & 25.0 & 76 \\
\hline Rothschild Collection (NHM) & Mainly pre- 1900 & 28.5 & 40.7 & 8.7 & 22.1 & 172 \\
\hline Hope Department (HD), Oxford & Mainly pre- 1900 & 29.0 & 34.2 & 8.5 & 28.3 & 272 \\
\hline Wiggins Collection (HD) & $1909-12$ & 15.8 & 66.3 & 4.0 & 13.9 & 101 \\
\hline Kome Island, Lake Victoria (HD) & 1946 & 46.8 & 38.0 & 1.3 & 13.9 & 79 \\
\hline Owen and Chanter (1968) & $1964-66$ & 37.4 & 49.6 & 3.6 & 9.4 & 530 \\
\hline Owiny & 1971-72 & 56.5 & 34.8 & 0.0 & 8.7 & 23 \\
\hline Owen, Gordon and Smith & 1991 & 71.1 & 23.7 & 2.8 & 2.4 & 211 \\
\hline
\end{tabular}

Values are percentages.

homogeneous $\left(\chi_{(6)}^{2}=6.295 ; 0.5>P>0.3\right)$ and all differ from the more recent ones in similar ways.

As shown in Table 4, the frequency of dorippus has declined steadily and consistently over the whole period; albinus also declined up to 1946 but has been fairly stable at low frequency since then. The alcippus phenotype shows the most dramatic change in frequency. It reached a low point of 16 per cent during 1909-12 and then increased steadily to reach 71 per cent in 1991. The apparent drop in frequency during 1964-66 may not be real as the standard errors for 1946, 1964-66 and 1971-72 overlap.

Figure 2 shows changes in frequency of the $a a$ ( + some $A a$ ) and $c c$ phenotypes for the period 1909-91. We start the graphs in 1900 by averaging the three pre-1900 collections (Table 4). The graph for the $c c$ phenotypes (aegyptius + alcippus) is based on direct observation; the data for the aa phenotypes (alcippus + albinus) are substantially inflated in Fig. 2 (by 30.3 per cent for the 1991 sample) because of the inclusion with the recessive $a a$ phenotype of some $A a$ butterflies (weak alcippus + weak albinus). This error is unavoidable, if the large random sample for 1964-66 and one of the museum samples were included (which is essential), to ensure comparable treatment of all samples: the 1964-66 data (Owen \& Chanter, 1968) are for butterflies marked and released and therefore not available for examination. The study was carried out before the genetics of $D$. chrysippus had been fully worked out and all individuals with some white in the hindwing were scored as alcippus (or albinus).

Regression coefficients are required to quantify with precision the changes of phenotype frequency over the period 1910-91; unfortunately, the small number of data points combined with large variation in sample sizes precludes such treatment. Further analysis has therefore to be limited to comparing phenotype frequencies at the start and end of this period and to examining the regularity of the changes by rank corre-

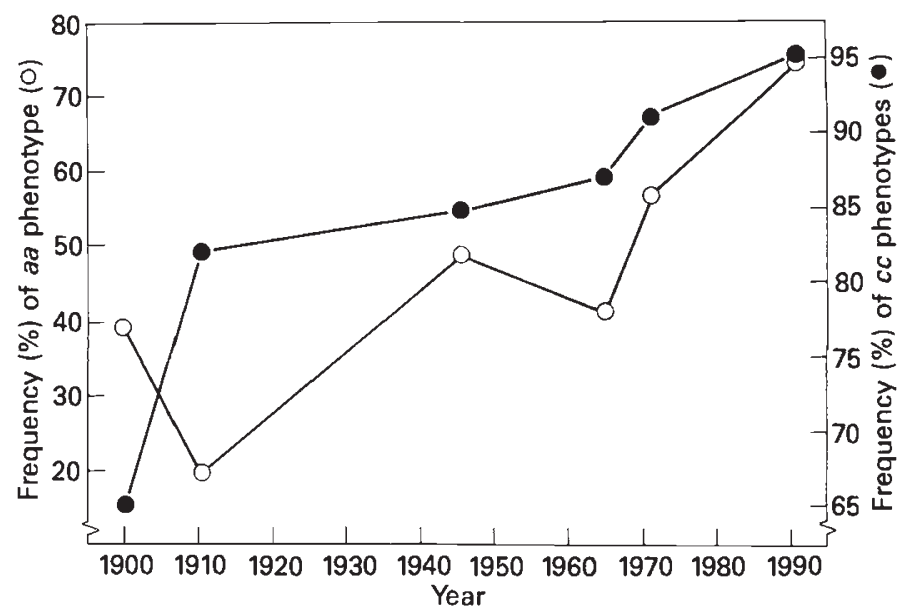

Fig. 2 Changes in frequency of the $a a$ and $c c$ phenotypes in Danaus chrysippus at Kampala, Uganda, during 1900-91.

lation. For the forewing phenotype, aegyptius + alcippus (the $c c$ phenotype) increased from 81.6 per cent to 94.9 per cent; a $z$-test on these data (arcsine transformed) shows that the change is very significant $(z=2.697,0.01>P>0.002)$. Moreover, the increase is probably regular (Kendall's $\tau=1, P=0.017$ ). Making due allowance for imperfections in the data, the $c c$ phenotype increased by an average of 0.16 per cent a year or 0.013 per cent per generation. The white hindwinged phenotype (alcippus + albinus, including weak (heterozygous) forms) increased even more significantly by 54.1 per cent, from 19.8 per cent in 1910 to 73.9 per cent in $1991(z=7.043, P<0.001)$ although in this case the increase cannot be accepted as regular $(\tau=0.8, P=0.08)$. The phenotype increase averages 0.67 per cent a year and 0.056 per cent per generation. If the Hardy-Weinberg equilibrium were assumed (see above), these observations would suggest frequency increases over 81 years of approximately 7 per cent for the $c$ allele and, more tentatively, in the order of 40 per cent for the $a$ allele. 
Sustained changes in allele frequency of the magnitude described could result from either introgression from populations to the west of Uganda, or powerful natural selection, or possibly a combination of both. We are unable to estimate changes at the $B$ locus, which was only recognized in 1973 (Clarke et al., 1973) but we expect substantial change to have occurred in view of the interactions between the $\mathrm{A}$ and $\mathrm{B}$ loci described above and between the closely linked $\mathrm{B}$ and $\mathrm{C}$ loci demonstrated in Tanzania.

\section{Discussion}

Substantial negative linkage disequilibrium (repulsion phase chromosomes in excess) between the $B$ and $C$ loci in $D$. chrysippus, based on breeding experiments, was described at Dar es Salaam (Smith, 1980); this result could not be tested or replicated in our small field sample from Kampala, where the frequency of both dominant alleles $(B$ and $C)$ is too low. Therefore, although the Dar es Salaam and Kampala populations may yet prove similar in having both linkage and nongametic disequilibria, on current evidence they differ fundamentally: the former shows strong negative linkage disequilibrium for the linked $\mathrm{B}$ and $\mathrm{C}$ loci in both sexes whereas the latter shows some other kind of disequilibrium, which we call genotypic, for both $A$ and $\mathrm{B}$ phenotypes considered alone (Table 2 ) and for A-B and $\mathrm{A}-\mathrm{C}$ combinations of unlinked loci (Table 3 ). The genotypic disequilibrium takes the form of marked sex differences for genotype frequency. The effect does not result from orthodox sex linkage (Clarke et al., 1973; Smith, 1975a). For all three loci, both genotype frequencies and additive or epistatic interactions with each of the other loci differ significantly between the sexes either at Dar es Salaam, Kampala or both.

As the $a$ and $b$ alleles are subject to adverse selection in females and positive selection in males, the opposing selection pressures, favouring alternative alleles in the two sexes, must result in balanced polymorphisms at both $\mathrm{A}$ and $\mathrm{B}$ loci. The genotypic disequilibria show that the $\mathrm{A}, \mathrm{B}$ and $\mathrm{C}$ locus polymorphisms in $D$. chrysippus, at Kampala as at Dar es Salaam, are interlocked in interactions with each other and with sex, possibly involving multiple feedback effects. Allele frequencies must be maintained by a balance of selective forces, acting on a coadapted gene complex (Lewontin, 1974), which operates differently in the two sexes. We predict that disequilibria of the types described here will in time be established as a general feature of all polymorphic East African populations of $D$. chrysippus but we are aware of the importance of replicating the Kampala and Dar es Salaam results in a large random sample from at least one other area.
The breeding data of Owen \& Chanter (1968) at Kampala show some unusual segregation patterns for both $\mathrm{A}$ and $\mathrm{BC}$ autosomes and sex chromosomes, in particular the occurrence of all-female broods at high frequency. Similar and more extensive results have been obtained at Dar es Salaam (Smith, 1975a,b, 1976b, 1980) and at Nairobi (I. J. Gordon, unpublished data). Features common to all three areas include distorted sex and phenotype ratios together with interaction between them. The causal genetic mechanisms are still under investigation and remain far from fully understood but we believe that sexautosome translocations and either nuclear or cytoplasmic lethal genes, at least one of which is male-specific, are involved.

A remarkable feature of our Kampala sample is the symmetry of genotype frequency differences between the sexes, the shortage of particular genotypes in one sex, when tested against the null hypothesis that autosomal gene frequencies are expected to be the same in both sexes, being almost exactly balanced by a surplus in the other (Table 3). We have evidence from Dar es Salaam suggesting that a Y-BC autosome translocation may be carried out by some females (the female is heterogametic in Lepidoptera), resulting in transmission of the normally autosomal $\mathrm{B}$ and $\mathrm{C}$ genes exclusively down the female line in all-female broods (Smith, $1976 \mathrm{~b}$ ). (This explanation was originally rejected in favour of meiotic drive but we now have evidence (unpublished data) to suggest that the all-female broods result from the death of male embryos.) These interpretations are supported by unpublished data from Nairobi (I. J. Gordon) and Mombasa (D. Schneider). Thus we have evidence for the occurrence of all-female broods over a large area in East Africa but from nowhere else.

There is, however, no evidence from Kenya or Tanzania for a sex-autosome translocation involving the A chromosome, which could provide an explanation, on similar grounds to that for the $B$ locus above, for the considerable sex differences in $A$ - and $a a$ genotype frequencies at Kampala. Therefore we speculate that a Y-A autosome translocation, inherited exclusively by females, mainly involving the $A$ allele, could explain the predominance of non-white hindwing in females compared with males at Kampala. It is probable that a combination of Y-autosome translocation polymorphisms and sex-specific mortality in ovo accounts for at least some of the differing genotype frequencies between sexes that we have described in this paper. Why such sex differences, whatever their origins and mode of inheritance, should have been subject to positive selection over much of East Africa is an open question that might in time be answered in terms of the comparative ecology or behaviour of the 
sexes. A clear understanding of the genetic mechanisms involved is obviously essential to further progress and will only be achieved through a breeding programme using Kampala material.

The changes in genotype frequency in $D$. chrysippus at Kampala over the past 90 years (Fig. 2), in particular the increase in frequency of alcippus, are similar in magnitude and time-span to the spread of the carbonaria allele in the moth Biston betularia (L.) (Geometridae) in the U.K. in the nineteenth century (Kettlewell, 1973). The main difference is that the moth has only one generation a year so that the evolutionary change in the butterfly involved approximately 12 times the number of generations, although within a comparable time-scale. The considerable genetic changes described here could result either from immigration and gene flow or entirely from natural selection in situ, or from a combination of the two. Our data provide no means of distinguishing all these possibilities, although two of our findings indicate emphatically that natural selection is involved. Firstly, the significant differences in genotype frequency between males and females for two of the three loci investigated indicate that, at individual loci, different genotypes have a selective advantage in the two sexes, a situation that must result in balanced polymorphisms, with equilibria determined by the relative strengths of the opposing selective forces. Secondly, the genotypic disequilibrium within sexes found for two pairs of unlinked autosomal loci constitutes prima facie evidence for the operation of natural selection at a higher level than the single gene locus or even the chromosome but rather at the level of the integrated gene complex or the genome (Lewontin, 1974; Gordon, 1987).

Although there is an impressive body of intuitive evidence suggesting that mimicry has been an important element in the evolution of polymorphism in $D$. chrysippus (Trimen, 1887; Poulton, 1912; Owen \& Chanter, 1968; Owen, 1971; Gordon \& Smith, 1989), it is probable that sexual selection, as found at Dar es Salaam (Smith, 1975b, 1981, 1984), and other factors which we are unable to identify, are also involved, especially in the evolution of sex differences.

There are 157 species of danaine butterflies in the world (Ackery \& Vane-Wright, 1984), D. chrysippus being the only one with a conspicuous colour and pattern polymorphism covering a substantial geographical area (some other species are polymorphic on a local scale where contact between geographical races creates hybrid zones). The question thus arises as to how the polymorphism originated and how it is maintained in an unpalatable species (Rothschild et al., 1975 ) that in theory should be monomorphic. Con- versely, why is $D$. chrysippus monomorphic over the greater part of its very extensive geographical range, for example in West Africa, tropical Asia and Australia?

Form alcippus $(a a c c)$ is the only form present in tropical Africa west of Cameroun and the simplest hypothesis is that western alleles have been and still are infiltrating central and eastern populations. One of us (D.A.S.S.) has proposed that the present sympatric colour forms are derived from previously allopatric subspecies which were isolated by forest barriers before or during the Pleistocene (Smith, 1980; Smith $e t$ al., 1988). D. chrysippus is a savanna butterfly and its present wide distribution in Africa must be a relatively recent phenomenon associated with a decrease in the area covered by forest as a result of a drier climate, accelerated by an unprecedented impoverishment of forest vegetation from human activities, especially in the last few hundred years. On this hypothesis there is now hybridization between three until recently allopatric subspecies: alcippus ( $a a B-c c$ and $a a b b c c)$ to the west of the formerly vast Chad Basin (Lake MegaChad), dorippus $\left(\begin{array}{lll}A A & b b & C C\end{array}\right)$ in the north-east (Somalia), and aegyptius $(A A B B C c)$ in the south. The absence of full dominance at all three diallelic loci supports our belief that hybridization is a recent event and unusual segregation for sex and other characters may indicate hybrid dysgenesis.

The hypothesis of an allopatric origin for the East and Central African polymorphism is supported by some persuasive evidence, the most pertinent being the present ranges of alcippus, dorippus and aegyptius, centred respectively in the west, north-east and south of Africa, where the populations remain monomorphic. In the precise form stated by Smith (1980), this hypothesis is undoubtedly a simplification of the true state of affairs. For example, aegyptius is by far the most frequent phenotype in Africa north of the Sahara, including the Nile Valley in Egypt and the Canary Islands, whereas alcippus is occasionally encountered, usually as weak alcippus, in localities as far apart as the Canary Islands (Owen \& Wiemers, 1992), Algeria (B. Samraoui, unpublished data) and Egypt (El-Aziz, 1991). The allopatric hypothesis clearly requires refinement as follows. Firstly, as $D$. chrysippus ranges without a break across North Africa and the Middle East to the Indian subcontinent and beyond, the derivation of the North African populations may be from the Asian subspecies chrysippus, which differs for several characters from the rather similar form from southern Africa. In recognizing these differences, Talbot (1943) accepted the name liboria Hulstaert (1931) for the distinctive race occupying the southern third of the continent. Secondly, the alcippus gene 
might have infiltrated to North Africa and the Canary Islands from across the Sahara at some time in the recent past when much of the area was dry savanna.

Another of us (D.F.O.) has proposed an hypothesis to account for the maintenance, as distinct from the origin, of the East African polymorphism in terms of Batesian mimicry theory (Owen, 1970). In Batesian mimicry the mimics, unless the models are exceedingly distasteful or toxic (Brower, 1960), must generally be less frequent than their models otherwise predators would learn that butterflies of particular colour patterns are usually palatable and the advantage gained by mimicry would soon be lost. Although Batesian mimicry confers advantages to mimics through deception, it is in general a threat to models as predators must occasionally gain experience on palatable species and thence proceed to attack unpalatable ones (Edmunds, 1974). In East Africa in particular, $D$. chrysippus is a model for a considerable variety of Batesian mimics, several of which (Hypolimnas misippus L., Pseudacraea poggei Dewitz, Mimacraea marshalli Talbot, Papilio dardanus Brown) are themselves polymorphic, with alternative forms mimicking different phenotypes of $D$. chrysippus (and in the latter case, other model species). However, in West Africa there are few mimics; here $D$. chrysippus is monomorphic and the alcippus phenotype has only one Batesian mimic, the alcippoides phenotype of the female $H$. misippus which is always relatively infrequent (Edmunds, 1969; Smith, 1976a). Thus, on this hypothesis, polymorphism in $D$. chrysippus was envisaged to have arisen sympatrically in areas where the species had become threatened by an overload of mimics; in contrast, where there were few mimics, polymorphism did not evolve.

These two hypotheses can now be dovetailed to provide an explanation both for the origin of the polymorphism and for its persistence over such a large area. Our data indicate a substantial increase in the frequency of alcippus in Uganda over the past 100 years, a period during which agricultural activities and forest destruction have provided vastly more suitable habitat for $D$. chrysippus. Indeed, our entire study area would have been under forest only a few hundred years ago. We therefore envisage that alcippus might be a relatively recent (post-Pleistocene) invader to Uganda from the west. During this time, say 20,000 years, the $a$ allele has reached the east coast of Kenya and Tanzania and spread through the Sudan to the Arabian peninsular and beyond (where its frequency is low), creating a west-east morph-ratio cline. The phenotype recurs, possibly as an independent mutant and sometimes at high frequency, in West Malaysia (Corbet \& Pendlebury, 1978) and Sumatra where it forms Müllerian co- mimicry rings with white hindwinged forms of Danaus affinis (Fabricius) and D. genutia (Cramer) (Ackery \& Vane-Wright, 1984). These authors suggest the possibility that the 'alcippus' pattern is primitive in $D$. chrysippus on the grounds that the $a$ allele is both recessive (it is actually only partially so) and is widespread at low frequency in the Oriental Region. Similar white hindwinged forms, however, also occur in races of the closely related $D$. gilippus in the New World and in D. plexippus in Hawaii. It follows that recurrent mutation for white hindwing in the genus Danaus is an equally feasible explanation.

We envisage that dorippus moved into Uganda from its heartland in the north-east at some unspecified but probably recent period and combined with alcippus to produce albinus (which exists only where alcippus and dorippus are sympatric) whereas aegyptius moved up from the south (and possibly down from the north as well). Similar events probably occurred and are occurring in other parts of the range of $D$. chrysippus where it is now polymorphic. The picture is further complicated by the fact that the species is seasonally migratory, thus promoting gene flow in some parts of its range but apparently not in others.

The polymorphism is probably now maintained sympatrically as suggested by Owen (1970). It is necessary, however, to incorporate the historical hypothesis of allopatric origins with that of sympatric maintenance of the polymorphism to overcome the problem pointed out by Turner (1977) that a novel aposematic mutant in a model species must be at a severe initial disadvantage as predators would fail to recognize it as distasteful. Even a gradual diversification of forms, through racial mingling and hybridization, could threaten the safety of all of them as predators experience increasing difficulty in relating several different images with distastefulness. In particular, there is evidence that the rarer forms of $D$. chrysippus are disproportionately at risk from predation (Smith, 1979). The answer to this paradox may lie in the existence in Uganda of up to four Müllerian co-mimicry rings comprising three sympatric savanna species, D. chrysippus, Acraea encedon and $A$. encedana, with many of the phenotypes of each species having matching forms in one or both of the others $(A$. encedon also has several non-mimetic forms). In this situation it is possible for a new form, whether mutant or novel immigrant, to join an existing Müllerian mimicry ring and obtain immediate protection. Moreover, if the various matching phenotypes of the three species had evolved by slow convergence in isolated allopatric refuges and all expanded their ranges to overlap and hybridize, more or less in unison and in response to the same habitat changes, this could explain the unique polymorphic Müllerian assemblages 
in East Africa. (It is possibly not a coincidence that all three species share a feature, rare in butterflies, unrelated to mimicry and highly suggestive of hybrid dysgenesis, namely female-biased populations with a high frequency of all-female brooding.) Unlike Batesian mimicry, these associations would not be expected to be number-dependent nor would the ranges of the various phenotypes necessarily show a perfect match because all are protected. We are currently investigating the two Acraea species to assess the extent of their polymorphic resemblances to different populations of $D$. chrysippus.

\section{Acknowledgements}

Our research in Uganda in 1991 was financed by a grant from the Royal Society of London. We are also grateful to the Nuffield Foundation for financial help through a grant made to Sir Cyril Clarke, Department of Genetics and Microbiology, University of Liverpool. Derek Whiteley drew the figures. The authors wish to thank an anonymous referee whose comments greatly improved the manuscript.

\section{References}

ACKERY, P. R. AND VANE-WRIGHT, R. I. 1984. Milkweed Butterflies: Their Cladistics and Biology, British Museum (Natural History), London.

BROWER, J. VAN z. 1960. Experimental studies in mimicry. Part IV. The reactions of starlings to different proportions of models and mimics. Am. Nat., 94, 271-282.

Clarke, C. A., SHEPPARD, P. M. AND SMITH, A. G. 1973. The genetics of fore and hindwing color in crosses between Danaus chrysippus from Australia and from Sierra Leone. J. Lep. Soc., 27, 73-77.

CORBET, A. S. AND PENDLEBURY, H. M. 1978. The Butterflies of the Malay Peninsular, 3rd edn, rev. Eliot, J. N. Kuala Lumpur, Malaysia.

EDMUNDS, M. 1969. Polymorphism in the mimetic butterfly Hypolimnas misippus L. in Ghana. Heredity, 24, 281-302.

Edmunds, M. 1974. Defence in Animals: a Survey of AntiPredator Defences. Longman, Harlow.

EL-Azız, S. A. 1991. Biological and morphological studies on Danaus chrysippus and Pieris rapae (Lepidoptera: Rhopalocera) in Assiut. Unpublished M.Sc Thesis, Assiut University, Egypt.

GORDON, I. J. 1984. Polymorphism of the tropical butterfly Danaus chrysippus L. in Africa. Heredity, 53, 583-593.

GORDON, I. J. 1987. Natural selection for rare and mimetic colour pattern combinations in wild populations of the diadem butterfly, Hypolimnas misippus L. Biol. J. Linn. Soc., 31, 1-23.

GORDON, I. J. AND SMITH, D. A. S. 1989. Genetics of the mimetic African butterfly Hypolimnas misippus: hindwing polymorphism. Heredity, 63, 409-425.
HULSTAERT, R. P. G. 1931. Lepidoptera Rhopalocera: Fam. Danaidae: Subfam. Danainae and Tellervinae. Genera Insectorum, Bruxelles, p. 193.

KeTtlewell, B. 1973. The Evolution of Melanism. Clarendon, Oxford.

LEWONTIN, R. C. 1964. The interaction of selection and linkage. I. General considerations; heterotic models. Genetics, 49 , 49-67.

LEWontin, R. C. 1974. The Genetic Basis of Evolutionary Change. Columbia University Press, New York.

OWEN, D. F. 1970. Mimetic polymorphism and the palatability spectrum. Oikos, 21, 333-336.

owEN, D. F. 1971. Tropical Butterflies. Clarendon, Oxford.

OWEN, D. F. AND CHANTER, D. O. 1968. Population biology of tropical African butterflies. 2. Sex ratio and polymorphism in Danaus chrysippus L. Rev. Zool. Bot. Afr., 78, $81-97$.

OWEN, D. F. AND WIEMERS, M. 1992. The butterflies of Fuerteventura. Entom. Gaz., 43, 87-92.

PIERRE, J. 1973. Etude d'un cycle mimétique ayant Danaus chrysippus (Linné) pour modèle et Hypolimnas misippus (Linné) (Nymphalidae) pour mime. Arch. Zool. Exp. Gen., 114, 73-96.

PIERRE, J. 1980. Variation geographique du polymorphisme et du mimétisme de Danaus chrysippus et d'Hypolimnas misippus en Afrique et en Asie. C. r. somm. Seanc. Soc. Biogeogr., 486, 179-187.

poulton, E. B. 1912. Comment on Col. Mander's paper. Proc. Roy. Ent. Soc. Lond., 1912, vii-ix.

ROTHSCHILD, M., VON EUW, J., REICHSTEIN, J., SMITH, D. A. S. AND PIERRE, J. 1975. Cardenolide storage in Danaus chrysippus (L.) with additional notes on D. plexippus (L.). Proc. Roy. Soc. Lond., B, 90, 1-31.

SMITH, D. A. S. 1975a. Genetics of some polymorphic forms of the African butterfly Danaus chrysippus L. (Lepidoptera: Danaidae). Entom. Scand., 6, 134-144.

SMITH, D. A. S. 1975b. All-female broods in the polymorphic butterfly Danaus chrysippus L. and their ecological significance. Heredity, 34, 363-371.

SMITH, D. A. S. $1975 \mathrm{c}$. Sexual selection in a wild population of the butterfly Danaus chrysippus L. Science, 187, 664-665.

SMITH, D. A. S. 1976a. Phenotypic diversity, mimicry and natural selection in the African butterfly Hypolimnas misippus L. (Lepidoptera: Nymphalidae). Biol. J. Linn. Soc., 8, 183-204.

SMITH, D. A. S. 1976b. Evidence for autosomal meiotic drive in the butterfly Danaus chrysippus L. Heredity, 36, 139-142.

SMITH, D. A. S. 1979. The significance of beak marks on the wings of an aposematic, distasteful and polymorphic butterfly. Nature, 281, 215-216.

SMITH, D. A. S. 1980. Heterosis, epistasis and linkage disequilibrium in a wild population of the polymorphic butterfly Danaus chrysippus (L.). Zool. J. Linn. Soc., 69, 87-109.

SMITH, D. A. S. 1981. Heterozygous advantage expressed through sexual selection in an African butterfly. Nature, 289, 174-175.

SMITH, D. A. S. 1984. Mate selection in butterflies: competition, coyness, choice and chauvinism. In: Vane-Wright, R. I. and 
Ackery, P. R. (eds) The Biology of Butterflies, Academic Press, London, Symp. R. Ent. Soc. Lond., 11, 225-244.

SMITH, D. A. S., SHOESMITH, E. A. AND SMITH, A. G. 1988. Pupal polymorphism in the butterfly Danaus chrysippus (L.): environmental, seasonal and genetic influences. Biol. J. Linn. Soc., 33, 17-50.

TALBot, G. 1943. Rev. notes on the genus Danaus Kluk (Lep. Rop. Danaidae). Trans. R. Ent. Soc. Lond., 93, 115-148.
TRIMEN, R. 1887. South African Butterflies: a Monograph of the Extra-Tropical Species. 1.London.

TURNER, J. R. G. 1977. Butterfly mimicry: the genetical evolution of an adaptation. In: Hecht, M. K., Steere, M. C. and Wallace, B. (eds) Evolutionary Biology, 10, 163-206, Plenum Press, New York. 